\title{
Therapy with Biologic Agents After Diagnosis of Solid Malignancies: Results from the Corrona Registry
}

\author{
Dimitrios A. Pappas, Sabrina Rebello, Mei Liu, Jennifer Schenfeld, YouFu Li, David H. Collier, \\ and Neil A. Accortt
}

ABSTRACT. Objective. Guidelines suggest that rheumatoid arthritis (RA) patients with previously treated solid malignancy may be treated as patients without such history. The recommendation is based on limited evidence, and rheumatologists and patients are frequently hesitant to start or continue biologic therapy after a cancer diagnosis. The objective of this study was to describe biologic use in real-world patients with RA following a malignancy diagnosis.

Methods. RA patients enrolled in the Corrona registry and diagnosed with solid malignancy with at least 1 followup visit within 12 months after diagnosis were included in this analysis. The proportion of patients continuing or initiating biological/targeted synthetic disease-modifying antirheumatic drug (bDMARD/tsDMARD) after diagnosis was estimated. Median time to initiation of bDMARD/tsDMARD after diagnosis was calculated using the Kaplan-Meier method and the proportion initiating biologic treatment in 6-month time intervals was estimated using the life-table method.

Results. There were 880 patients who met inclusion criteria with 2585 person-years total followup time postdiagnosis. Of those, 367 (41.7\%) were treated with bDMARD/tsDMARD within 12 months preceding malignancy, of whom $270(30.7 \%)$ were taking such agents at first postdiagnosis visit. Forty-four (5\%) switched biologic agents within 36 months and an additional 90 patients (10.2\%) started a biologic. The majority of bDMARD/tsDMARD initiations during followup was a tumor necrosis factor inhibitor (TNFi; 53.5\%).

Conclusion. In real-world practice, nearly one-third of RA patients with a cancer diagnosis were treated with systemic therapy in the immediate visit after malignancy diagnosis and a considerable percentage of malignancy survivors initiated biologic therapy within 3 years. The majority of bDMARD/tsDMARD initiations post-malignancy diagnosis was a TNFi. (First Release August 1 2019; J Rheumatol 2019;46:1438-44; doi:10.3899/jrheum.171457)

Key Indexing Terms:

\section{RHEUMATOID ARTHRITIS}

From Columbia University, New York, New York; Corrona LLC, Waltham, Massachusetts; DOCS Global Inc., North Wales, Pennsylvania; University of Massachusetts Medical School, Worcester, Massachusetts; Amgen Inc., Thousand Oaks, California, USA.

This study was sponsored by Corrona LLC and the analysis was funded by Amgen. Only Corrona has access to the study data and Corrona statisticians completed all of the analyses; all authors contributed to the interpretation of the results. Corrona LLC has been supported through contracted subscriptions in the last 2 years by AbbVie, Amgen, Boehringer Ingelheim, Bristol-Myers Squibb, Crescendo, Eli Lilly and Co., Genentech, Gilead, GSK, Horizon Pharma USA, Janssen, Momenta Pharmaceuticals,

Novartis, Pfizer Inc., Roche, Sun-Merck, UCB, and Valeant. N.A. Accortt and D.H. Collier are employed by Amgen Inc. and own Amgen Inc. stock. J. Schenfeld is a contractor for DOCS Global Inc. and has received salary support from Amgen Inc. S. Rebello and M. Liu are employed by Corrona LLC. D.A. Pappas is employed by Corrona, is affiliated with Columbia University, and is an instructor at Novartis.

D.A. Pappas, MD, MPH, Columbia University, and Corrona LLC; S. Rebello, MPH, Corrona LLC; M. Liu, PhD, Corrona LLC; J. Schenfeld, MPH, DOCS Global Inc.; Y.F. Li, MD, MPH, University of Massachusetts Medical School; D.H. Collier, MD, Amgen Inc.; N.A. Accortt, PhD, Amgen Inc.

Address correspondence to Dr. D.A. Pappas, Columbia University, College of Physicians \& Surgeons, 630 W. 168th St., P\&S Building, Suite 10-445, New York, New York 10032,USA. E-mail:dpappas@corrona.org Full Release Article. For details see Reprints and Permissions at jrheum.org Accepted for publication March 6, 2019

\section{MALIGNANCY BIOLOGICS}

Guidelines suggest that rheumatoid arthritis (RA) patients with previously treated solid malignancy may be treated as patients without such history ${ }^{1}$. However, rheumatologists and patients are frequently hesitant to continue or start biological disease-modifying antirheumatic drug (bDMARD) therapy after a cancer diagnosis. Treating physicians may be concerned that biologic agents may interfere with the immune response to cancer and increase the risk for new malignancies or recurrence of previously diagnosed malignancies. The aforementioned concerns are fueled by the linking of biologic agents with an increased risk for skin cancers, albeit not for solid tumors or lymphoproliferative malignancies ${ }^{2}$. In addition, early clinical trial signals suggesting a potential increase of risk for malignancies in patients treated with tumor necrosis factor inhibitors (TNFi) may have established fear regarding the effect of biologic agents on tumorigenesis, even though an increased risk for carcinogenesis remains unverified by considerable observational data ${ }^{3-11}$. Further, physicians are concerned that the safety of biologic therapy use after diagnosis of cancer has not been clearly established, specifically in terms of prognosis, progression, and relapse ${ }^{3}$, although the limited

Personal non-commercial use only. The Journal of Rheumatology Copyright @ 2019 . All rights reserved. 
available evidence so far shows that recurrence of malignancy is not increased in patients treated with biologic agents ${ }^{3,11}$.

Compared to the general population, patients with RA have a higher risk of malignancy, specifically lymphoma and lung cancer ${ }^{12}$. Thus, treating RA patients with a concurrent malignancy is not rare and the need to take care of cancer patients with active joint disease necessitating aggressive therapy with biologics frequently occurs in the daily practice. Less disease activity would allow such patients to have better quality of life and improved functionality during cancer therapy. Further, aggressive therapy of RA would prevent joint damage, which would allow a return to normal life after cancer therapy. The goal of the present study was to describe the real-world bDMARD and targeted synthetic DMARD (tsDMARD) use in patients with RA following a solid malignancy diagnosis.

\section{MATERIALS AND METHODS}

Patient population. The Corrona registry is an independent, prospective, observational cohort of patients with RA recruited at 169 private and academic practice sites across 40 states in the United States; additional details have been published previously ${ }^{13,14,15,16}$. As of April 1, 2017, data on 45,722 patients with RA had been collected. This translates to information on 343,798 patient visits and 155,779 person-years (PY) of followup observation time. The mean duration of patient followup is 4.3 years (SD 3.4) and median 3.5 years. The Corrona registry was established in accordance with the Declaration of Helsinki. All participating investigators were required to obtain full board approval for conducting noninterventional research involving human subjects. Sponsor approval and continuing review was obtained through a central institutional review board (IRB; New England Independent Review Board, NEIRB No. 120160610). For academic investigative sites that did not receive a waiver to use the central IRB, full board approval was obtained from the respective governing IRB and documentation of approval was submitted to Corrona prior to initiating any study procedures. All registry patients were required to provide written informed consent and authorization prior to participating.

Study population. This analysis included patients with RA enrolled in the Corrona registry between March 1, 2002, and March 31, 2016. Eligible patients were required to have a new onset of solid malignancy during followup in the registry and at least 1 followup visit within 12 months of malignancy diagnosis. The index date was defined as the first Corrona visit after the diagnosis of a malignancy. Patients with a history of any previous solid cancer or a diagnosis of hematologic cancers (such as lymphoma, leukemia, or multiple myeloma) were excluded from the analysis. Patients with nonmelanoma skin cancers (NMSC; squamous and basal cell skin carcinomas) diagnosed after enrollment to the registry were not included in the analysis and were not counted as part of the malignancies reported in this work. Followup time was counted from the index date until the last followup visit in Corrona or until the initiation of the first bDMARD or tsDMARD following the malignancy diagnosis. The bDMARD included TNFi medications (adalimumab, certolizumab pegol, etanercept, golimumab, and infliximab) and non-TNFi medications (abatacept, anakinra, rituximab, and tocilizumab). The tsDMARD included tofacitinib citrate.

Measures and data collection. Data are collected from both patients and their treating rheumatologists, who gather information on disease duration, prognosis, disease severity and activity, medical comorbidities (including malignancies, use of medications including biologics, conventional sDMARD, and prednisone), and adverse events. Followup assessments are requested at least every 6 months and completed during routine clinical encounters.

Study outcomes. Clinical characteristics were evaluated as of the index date.
The primary outcome was the proportion of patients continuing or initiating bDMARD or tsDMARD after a solid malignancy diagnosis.

Statistical analysis. The proportion of patients initiating a bDMARD or tsDMARD after diagnosis was estimated. Median time to the first initiation of a bDMARD/tsDMARD after diagnosis was calculated using the Kaplan-Meier method. The proportion of patients initiating bDMARD treatment in 6-month intervals was estimated using the life-table method.

\section{RESULTS}

Of 42,619 patients with RA historically enrolled in Corrona at the time of this analysis, 934 patients had an incident solid malignancy after registry enrollment. Of them, 880 patients had at least 1 followup visit within 12 months after diagnosis, constituting the final analysis cohort. There were 763 patients who had an incident NMSC during followup and were not included in this analysis. The mean (SD) time from the visit preceding the diagnosis of malignancy to the first visit after the malignancy diagnosis was 8.4 (7.5) months. Total followup time for the study population after the index visit was 2585.6 PY. Demographic and clinical characteristics at the first registry visit following malignancy diagnosis (index visit) are shown in Table 1 . Patients were mostly females (67\%), had a mean RA disease duration prior to malignancy diagnosis of 14.1 years, and a mean age of 66.6 years. Baseline mean Clinical Disease Activity Index (CDAI) at index date was 11.2 , with $38 \%$ of patients being in moderate or high disease activity. The most frequent cancer types were breast cancer $(21 \%)$ and melanoma skin cancer (9\%).

As seen in Table 2, 367 (41.7\%) patients were taking a biologic agent prior to the diagnosis of malignancy. As seen in Table 3, at the first registry visit following a diagnosis of malignancy (index visit), 270 (30.7\%) of 880 patients were treated with a biologic agent or tsDMARD. The majority of them (79.2\%) were taking a TNFi. Out of the 270 patients, $187(69.3 \%)$ were taking the same bDMARD/tsDMARD that they were taking immediately prior to malignancy diagnosis. Table 3 displays the numbers of biologic initiations, switches, and discontinuations over the first 3 years of followup. At the end of the 3-year period, 350 patients remained in followup in the registry. Of those lost to followup before 3 years, an exit from the registry visit has been recorded for 240 patients; 63 exited the registry because of death. As shown in Table 3, a decreasing percentage of patients were treated with a bDMARD or tsDMARD during this followup period: $34.7 \%$ of the patient cohort at the end of the 6-month interval, 25.1\% at the end of the 24-month interval, and $19.1 \%$ at the end of the 36-month interval.

During these 36 months of followup, 90 patients initiated a biologic. This translates to $14.8 \%(90 / 610)$ of the total number of patients not taking a biologic at the index visit. Of the 350 with at least 3 years of followup, 275 did not start a biologic within 3 years of malignancy diagnosis. In addition, there were 44 biologic switches among the 270 patients taking a biologic at index visit (16.3\%) during the 3-year followup period. Among them, 50 patients (18.5\%) stopped

Personal non-commercial use only. The Journal of Rheumatology Copyright (c) 2019. All rights reserved. 
Table 1. Patient demographic and clinical characteristics at index visit/baseline*.

\begin{tabular}{|c|c|}
\hline Characteristics & Incident Malignancy, $\mathrm{n}=880$ \\
\hline Sex, $n$ & 878 \\
\hline Female & $592(67.4)$ \\
\hline Age, $n$ & 878 \\
\hline Mean (SD), median (IQR) & $66.6(10.5), 67(59-74)$ \\
\hline Duration of RA, $\mathrm{n}$ & 878 \\
\hline Mean (SD), median (IQR) & $14.1(10.7), 11(6-20)$ \\
\hline Race, $\mathrm{n}$ & 864 \\
\hline White & $792(91.7)$ \\
\hline African American & $47(5.4)$ \\
\hline Asian & $9(1)$ \\
\hline Other & $16(1.9)$ \\
\hline Education, $\mathrm{n}$ & 844 \\
\hline College or above & $471(55.8)$ \\
\hline Smoking status, $\mathrm{n}$ & 878 \\
\hline Never smoker & $395(45)$ \\
\hline Previous smoker & $349(39.7)$ \\
\hline Current smoker & $134(15.3)$ \\
\hline Weight, lbs, $\mathrm{n}$ & 880 \\
\hline Mean (SD), median (IQR) & $172.7(41.4), 170(145-195)$ \\
\hline BMI, $\mathrm{n}$ & 877 \\
\hline Underweight & $21(2.4)$ \\
\hline Normal weight & $268(30.6)$ \\
\hline Overweight & $312(35.6)$ \\
\hline Obese & $276(31.5)$ \\
\hline Work status, $\mathrm{n}$ & 859 \\
\hline Full-time & $174(20.3)$ \\
\hline Part-time & $64(7.5)$ \\
\hline At home & $73(8.5)$ \\
\hline Student & $9(1)$ \\
\hline Disabled & $111(12.9)$ \\
\hline Retired & $428(49.8)$ \\
\hline Insurance, $\mathrm{n}$ & 862 \\
\hline None & $3(0.3)$ \\
\hline Private & $581(67.4)$ \\
\hline Medicaid & $43(5)$ \\
\hline Medicare & $464(53.8)$ \\
\hline $\mathrm{RF} / \mathrm{CCP}$ status, $\mathrm{n}$ & 602 \\
\hline Positive & $468(77.7)$ \\
\hline Comorbid conditions, $\mathrm{n}$ & 880 \\
\hline History of CVD & $68(7.7)$ \\
\hline History of serious infection & $75(8.5)$ \\
\hline Solid cancer type, $\mathrm{n}$ & 880 \\
\hline Breast cancer & $190(21.6)$ \\
\hline Lung cancer & $78(8.9)$ \\
\hline Melanoma skin cancer & $83(9.4)$ \\
\hline Prostate cancer & $61(6.9)$ \\
\hline Uterus and ovary cancer & $36(4.1)$ \\
\hline Colon cancer & $33(3.8)$ \\
\hline Bladder cancer & $20(2.3)$ \\
\hline Thyroid cancer & $17(1.9)$ \\
\hline Other cancer & $362(41.1)$ \\
\hline CDAI, n & 858 \\
\hline Mean (SD), median (IQR) & $11.2(12.1), 8(3-16)$ \\
\hline CDAI categories, $\mathrm{n}$ & 858 \\
\hline Remission & $218(25.4)$ \\
\hline Low & $311(36.2)$ \\
\hline Moderate & $197(23.0)$ \\
\hline High & $132(15.4)$ \\
\hline
\end{tabular}

Table 1. Continued.

\begin{tabular}{lc}
\hline Characteristics & Incident Malignancy, $\mathrm{n}=880$ \\
\hline Period of cancer diagnosis, $\mathrm{n}$ & 880 \\
$2002-2006$ & $124(14.1)$ \\
$2007-2012$ & $491(55.8)$ \\
$2013-2016$ & $265(30.1)$ \\
\hline
\end{tabular}

Values are n (\%) unless otherwise specified. * The index date is the first Corrona visit following a malignancy diagnosis, or the enrollment visit for those with a history of malignancy prior to enrollment. Variable reported at index date, unless otherwise noted. IQR: interquartile range; BMI: body mass index; RF: rheumatoid factor; CCP: cyclic citrullinated peptide; CVD: cardiovascular disease; CDAI: Clinical Disease Activity Index; RA: rheumatoid arthritis.

Table 2. Medication treatment prior to index visit.

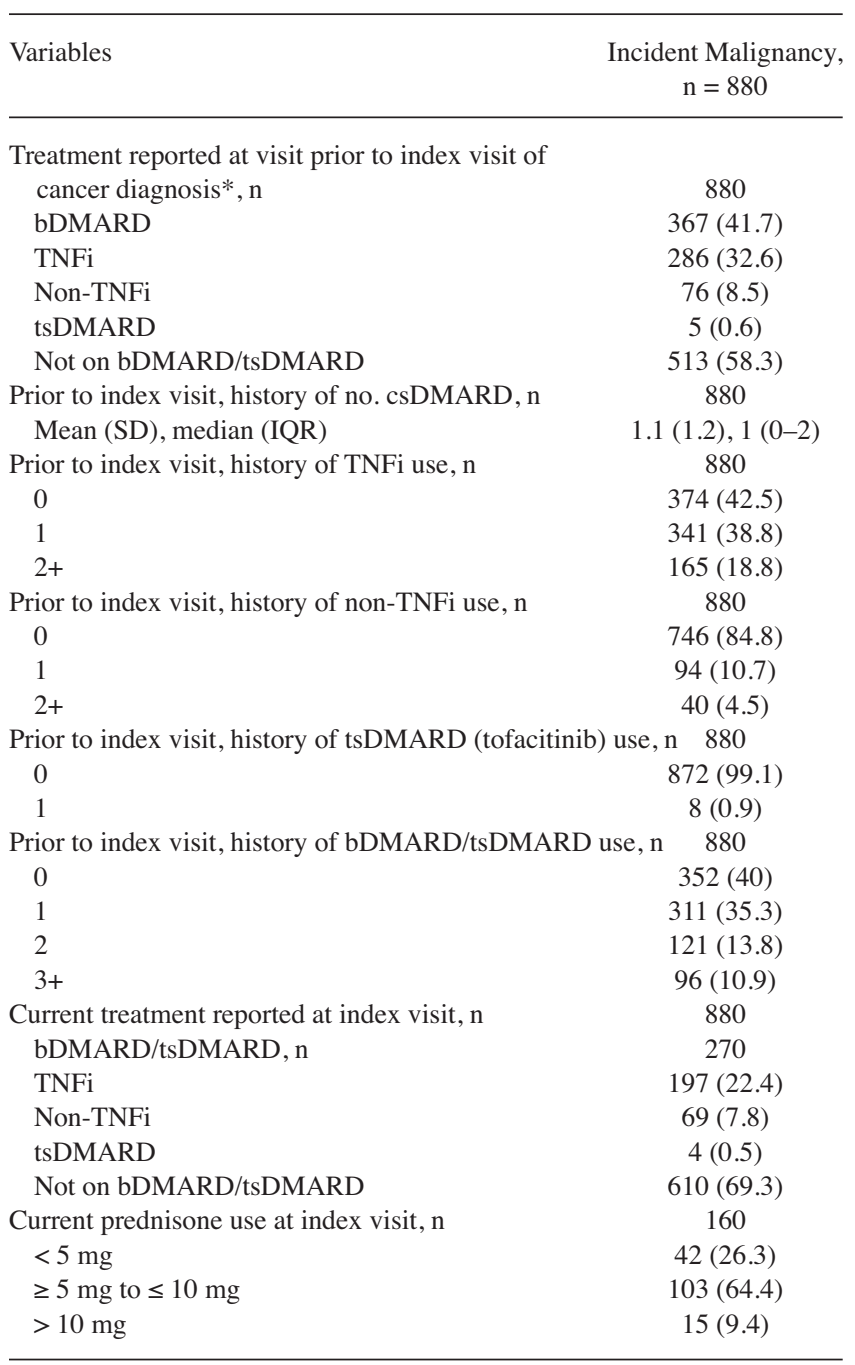

Values are $\mathrm{n}(\%)$ unless otherwise specified. ${ }^{*}$ Treatment reported at the visit prior to cancer diagnosis. Out of 880 patients, 734 patients had a visit within 12 months before the index date. The mean (SD) months from index date to the visit prior to cancer (solid tumor only) diagnosis is 8.4 (7.5) months. bDMARD: biological disease-modifying antirheumatic drug; TNFi: tumor necrosis factor inhibitor; tsDMARD: targeted synthetic DMARD; csDMARD: conventional synthetic DMARD; IQR: interquartile range. 
Table 3. Clinical characteristics in 6-month intervals after diagnosis of solid malignancy.

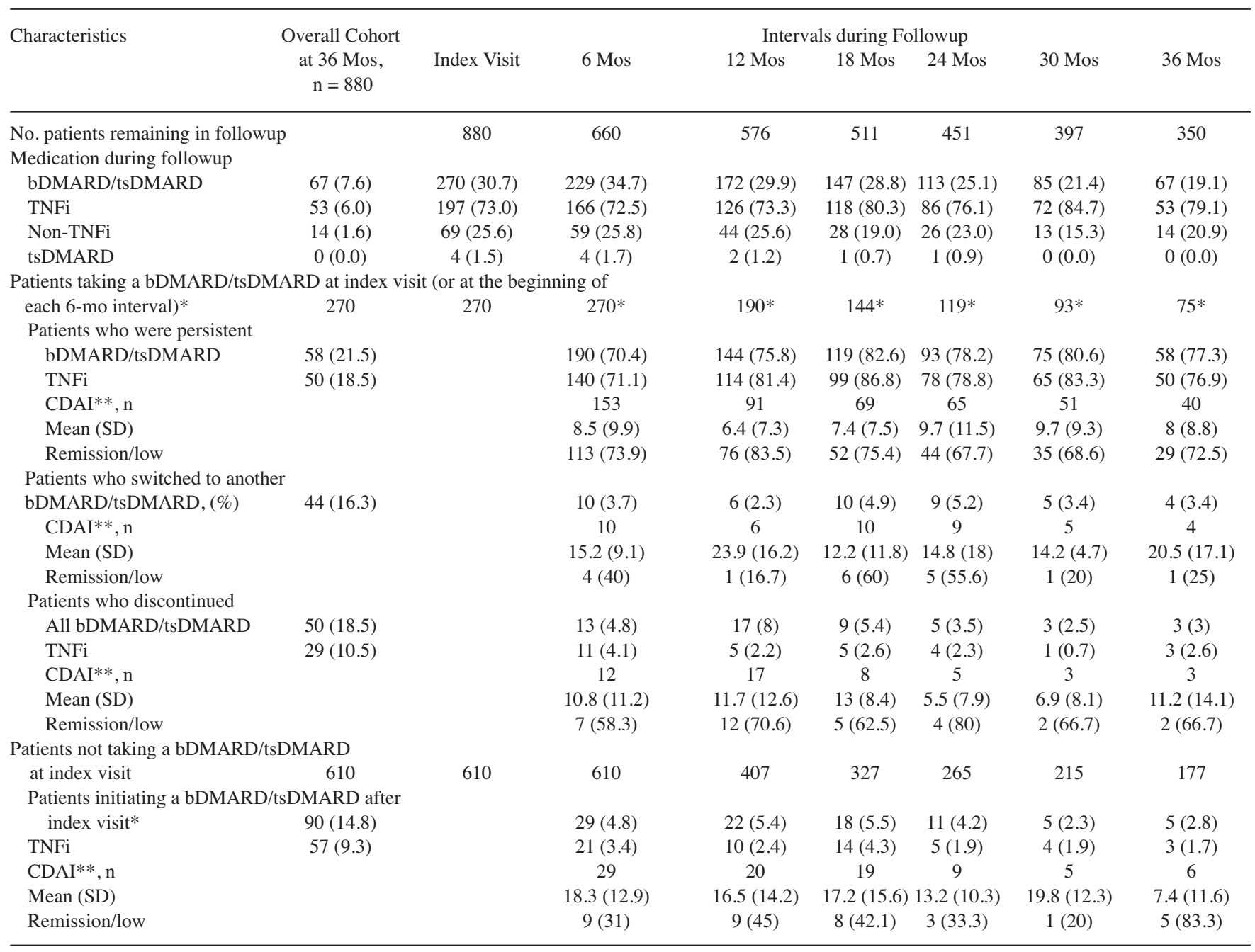

Values are $\mathrm{n}(\%)$ unless otherwise specified. Of the 190 patients who were persistent, 187 were taking the same biologic/tsDMARD. * The no. reported for each interval correspond to the beginning of the interval. The summation of the no. patients with changes during each interval (patients persistent with bDMARD/tsDMARD + patients who switched to another bDMARD/tsDMARD + patients who discontinued all bDMARD/tsDMARD) does not equal the number at the beginning of each interval because it does not take into account loss to followup or deaths. Such patients may have contributed to changes reported during each interval before they died or were lost to followup. ** CDAI is reported at the visit closest to the end of the time interval. bDMARD: biological disease-modifying antirheumatic drug; tsDMARD: targeted synthetic DMARD; TNFi: tumor necrosis factor inhibitor; CDAI: Clinical Disease Activity Index.

their biologic agent during the first 3 years of followup.

Patients who continued taking the initial biologic had relatively better control of disease activity (mean CDAI 8.5), while those who switched or started a new biologic had higher levels of disease activity (CDAI 15.2 and 18.3, respectively).

The Kaplan-Meier curve for the time to initiation of a new biologic after the diagnosis of malignancy is shown in Figure 1. Based on the interquartile range, $25 \%$ of the patient cohort started a biologic by Month 36 . The median time to initiation of the first bDMARD/tsDMARD after the diagnosis of a malignancy was 114.8 months, about 10 years.

There was a total of $170(19.3 \%)$ bDMARD and tsDMARD initiations during the entire followup. The majority (53.5\%) was TNFi (Figure 2). Of the 58 who continued taking their initial bDMARD during 3 years of followup, $86 \%$ were taking a TNFi (Figure 2).

We also evaluated the 134 bDMARD/tsDMARD initiations occurring during the first 36 months of followup based on the history of biologic exposure up to the moment of the index visit. As shown in Table 4, patients with a history of biologic exposure prior to malignancy diagnosis were more likely to start a biologic in the 36 months following the index visit.

\section{DISCUSSION}

There is relative uncertainty regarding the management of biologic therapy in patients with RA who are diagnosed with

Personal non-commercial use only. The Journal of Rheumatology Copyright $\subset$ 2019. All rights reserved. 


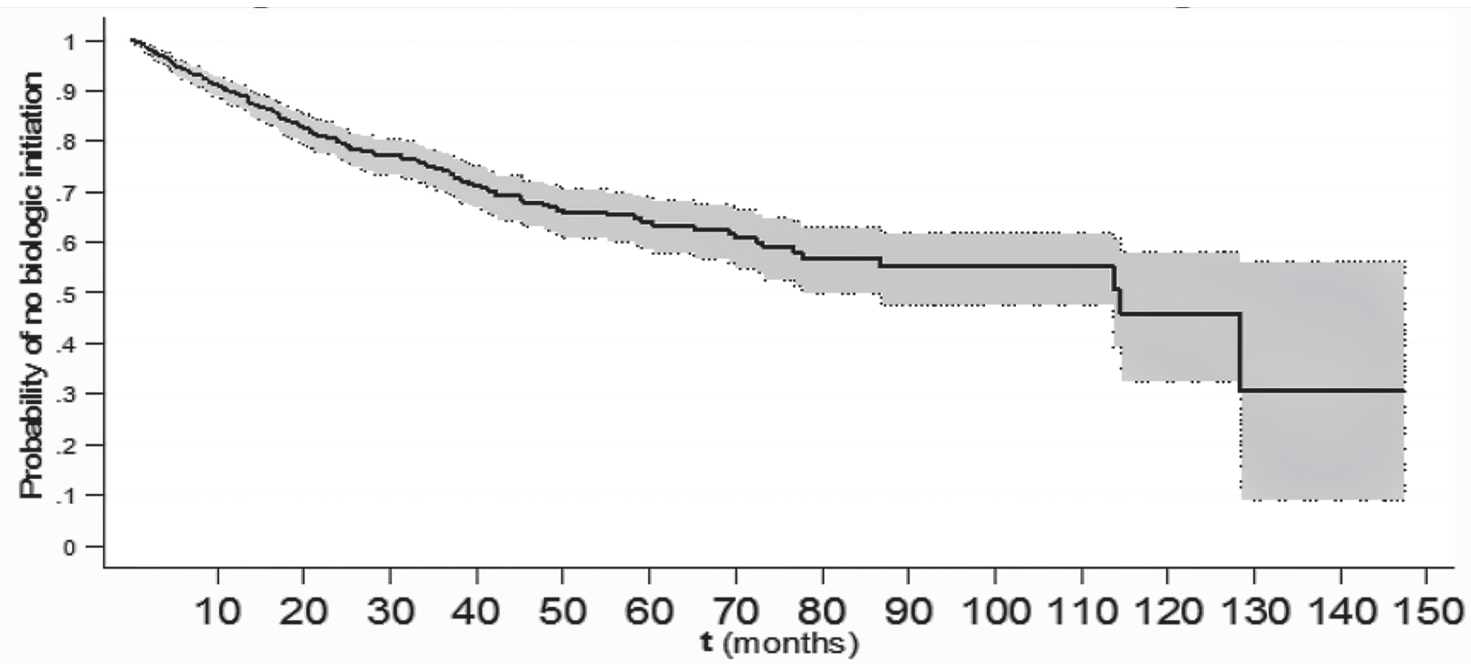

\section{Number at risk}

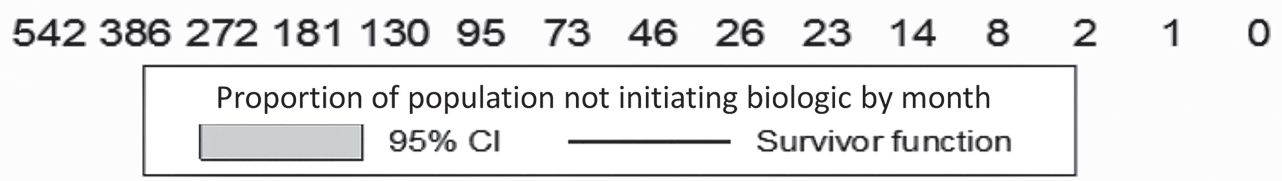

Figure 1. Kaplan-Meier curve for month $(95 \% \mathrm{CI})$ from diagnosis of cancer to the initiation of the biologic in Corrona. Number at risk is represented at 10 -month intervals.

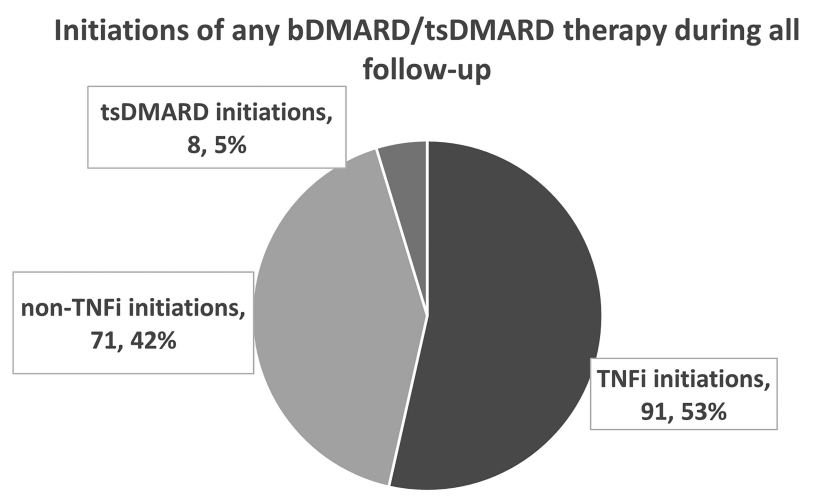

- TNFi initiations non-TNFi initiations $\quad$ tsDMARD initiations
Patients remaining on initial bDMARD/tsDMARD therapy during all follow-up

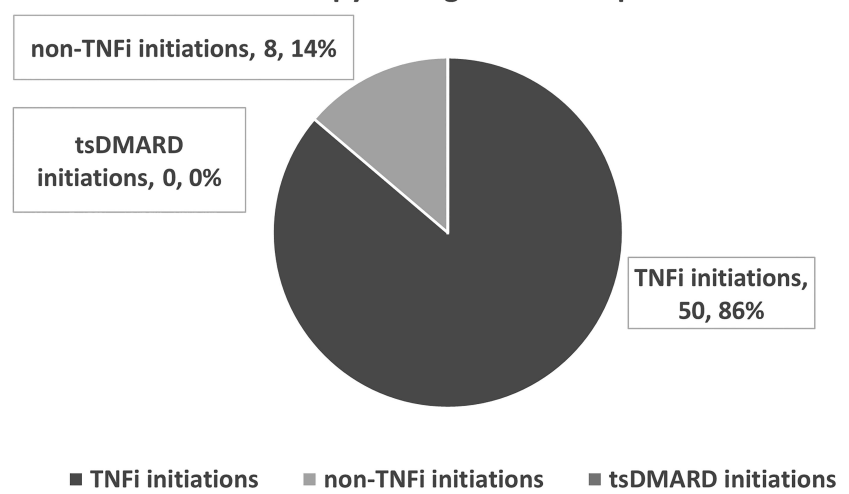

Figure 2. Initiations of bDMARD/tsDMARD during followup and the patients remaining on initial therapy during followup. bDMARD: biological diseasemodifying antirheumatic drug; tsDMARD: targeted synthetic DMARD; TNFi: tumor necrosis factor inhibitor.

a solid malignancy. However, clinicians are frequently faced with a patient who has recently been diagnosed with a cancer and has active disease that necessitates therapy with biologics. Given that several cancers may be curable today, aggressive therapy of joint disease may ensure a functional life after cancer without joint damage and disability. In addition, mobility and intact functionality without joint pain or damage are important for patients even during therapy for cancer, regardless of the cancer prognosis. This is a challenging position for both physicians and patients because of the still-lingering fears that biologics may increase the chance for a malignancy recurrence or may interfere with the effectiveness of chemotherapy or radiation treatment, or may hamper the healing process of frequently extensive surgeries needed for the therapy of cancer. Such fears are not supported by the available evidence ${ }^{2,8,9,10,16}$. This is probably the reason why more recent guidelines indicate that if a patient within 5 years from a solid malignancy diagnosis needs a biologic, then the biologic therapy may be started ${ }^{17}$. However, data supporting such a decision are limited.

This study aimed to describe what happens in real-world practice using a large cohort of patients with RA who were 
Table 4. Treatment history at index visit and initiation of biologics during the 36 months after cancer diagnosis.

\begin{tabular}{lcc}
\hline Variables & $\begin{array}{c}\text { Not Taking a Biologic at Index Visit } \\
\text { and No History of Biologic Use }\end{array}$ & $\begin{array}{c}\text { Not Taking a Biologic at Index Visit } \\
\text { but with History of Biologic Therapy }\end{array}$ \\
\hline $\begin{array}{l}\text { No. patients* } \\
\text { Patients starting a biologic by } 36 \text { mos postindex }\end{array}$ & $\begin{array}{c}347(39.4) \\
25(7.2)\end{array}$ & $\begin{array}{c}263(29.9) \\
65(24.7)\end{array}$ \\
\hline
\end{tabular}

Values are n (\%). * Eight patients did not have a registry visit prior to cancer diagnosis.

diagnosed with solid malignancies. The study aimed not to provide guidance as to how to manage patients diagnosed with a cancer or to investigate how patients respond to biologic therapy after diagnosis of cancer, but only to describe how treating rheumatologists across the USA handle biologic therapies after a diagnosis of cancer.

In real-world practice, nearly one-third of patients with RA were taking bDMARD and tsDMARD therapies in the first visit (about 6 mos) after diagnosis of a solid malignancy. Up to $5 \%$ of patients still in followup were starting a biologic in every 6-month interval of followup. The majority of bDMARD/tsDMARD initiations was with a TNFi medication.

We showed that people with a history of biologic exposure were more likely to be treated with a biologic after a malignancy diagnosis. This most likely reflects a more active disease that necessitated the initiation/continuation of a biologic agent.

The strength of this study is that the registry allowed us to detect a relatively large number of solid malignancies for the "average" patient treated in both academic and private rheumatology practices. A limitation of the study is that we were not able to ascertain the status of the percentage of patients lost to followup; the most likely explanation of this percentage of patients lost to followup is death from malignancy or no return to the rheumatologist while the patients were receiving therapy for their malignancy. Corrona has started to collect personal identifying information in recent years but these were not available in the early phases of the registry. Thus, it was not possible to link to other databases to determine how many of the patients diagnosed with malignancy and lost to followup died. Based on the data collected at the practices participating in Corrona, about $25 \%$ of the patients reported in this analysis as lost to followup were confirmed to have died; the living status of the rest of the patients remains unknown currently.

Our results may not be generalizable to hematological cancers that were excluded from this analysis. We also excluded NMSC because, in general, they are not considered life-threatening. Further, the severity of cancer was not considered, and all solid malignancies were included in this analysis regardless of stage or histology aggressiveness. Thus, it cannot be said whether biologics were initiated or continued in less aggressive malignancies. Because the malignancy diagnosis for patients occurred between registry visits, there is a potential for misclassification of therapy and any changes that were made as a result of the diagnosis before the index visit. Corrona was not collecting information for temporary interruptions of bDMARD/tsDMARD until recently. For the data presented in this analysis, possible temporary interruptions of therapy between the malignancy diagnosis and the index visit will not have been recorded. Finally, patients with high disease activity were not separated from those with low disease activity in this research, to further specifically investigate the management of patients in need of augmentation of therapy.

To our knowledge, this study provides the first description of a large RA cohort with solid malignancies and how rheumatologists treat these patients. Based on these results, it appears that rheumatologists are comfortable either continuing or initiating biologic therapy (primarily TNFi) in this select group of patients with RA. Further study is needed to determine the longterm outcome (survival, recurrence of malignancy but also damage of joints) of patients with cancer treated with biologics, as well as how biologics may interfere with antineoplastic therapy and healing after oncologic surgeries.

\section{REFERENCES}

1. Singh JA, Saag KG, Bridges SL Jr., Akl EA, Bannuru RR, Sullivan MC, et al. 2015 American College of Rheumatology Guideline for the Treatment of Rheumatoid Arthritis. Arthritis Rheumatol 2016;68:1-26.

2. Wolfe F, Michaud K. Biologic treatment of rheumatoid arthritis and the risk of malignancy: analyses from a large US observational study. Arthritis Rheum 2007;56:2886-95.

3. Askling J, Bongartz T. Malignancy and biologic therapy in rheumatoid arthritis. Curr Opin Rheumatol 2008;20:334-9.

4. Stone JH, Holbrook JT, Marriott MA, Tibbs AK, Sejismundo LP, Min YI, et al; Wegener's Granulomatosis Etanercept Trial Research Group. Solid malignancies among patients in the Wegener's Granulomatosis Etanercept Trial. Arthritis Rheum 2006;54:1608-18.

5. Rennard SI, Fogarty C, Kelsen S, Long W, Ramsdell J, Allison J, et $\mathrm{al}$; COPD Investigators. The safety and efficacy of infliximab in moderate to severe chronic obstructive pulmonary disease. Am J Respir Crit Care Med 2007;175:926-34.

6. Bongartz T, Sutton AJ, Sweeting MJ, Buchan I, Matteson EL, Montori V. Anti-TNF antibody therapy in rheumatoid arthritis and the risk of serious infections and malignancies: systematic review and meta-analysis of rare harmful effects in randomized controlled trials. JAMA 2006;295:2275-85.

7. Costenbader KH, Glass R, Cui J, Shadick N. Risk of serious infections and malignancies with anti-TNF antibody therapy in rheumatoid arthritis. JAMA 2006;296:2201.

8. Setoguchi S, Solomon DH, Weinblatt ME, Katz JN, Avorn J, Glynn $\mathrm{RJ}$, et al. Tumor necrosis factor alpha antagonist use and cancer in

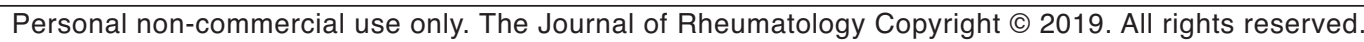


patients with rheumatoid arthritis. Arthritis Rheum 2006; 54:2757-64.

9. Geborek P, Bladstrom A, Turesson C, Gulfe A, Petersson IF, Saxne $\mathrm{T}$, et al. Tumour necrosis factor blockers do not increase overall tumour risk in patients with rheumatoid arthritis, but may be associated with an increased risk of lymphomas. Ann Rheum Dis 2005;64:699-703.

10. Strangfeld A, Hierse F, Rau R, Burmester GR, Krummel-Lorenz B, Demary $\mathrm{W}$, et al. Risk of incident or recurrent malignancies among patients with rheumatoid arthritis exposed to biologic therapy in the German biologics register RABBIT. Arthritis Res Ther 2010;12:R5.

11. Smitten AL, Simon TA, Hochberg MC, Suissa S. A meta-analysis of the incidence of malignancy in adult patients with rheumatoid arthritis. Arthritis Res Ther 2008;10:R45.

12. Kremer JM. The Corrona US registry of rheumatic and autoimmune diseases. Clin Exp Rheumatol 2016;34:S96-9.
13. Kremer JM. The CORRONA database. Autoimmun Rev 2006; 5:46-54.

14. Kremer JM. The CORRONA database. Clin Exp Rheumatol 2005;5 Suppl 39:S172-7.

15. Kremer J. The CORRONA database. Ann Rheum Dis 2005;64 Suppl 4:iv37-41.

16. Mercer LK, Lunt M, Low AL, Dixon WG, Watson KD, Symmons DP, et al; BSRBR Control Centre Consortium. Risk of solid cancer in patients exposed to anti-tumour necrosis factor therapy: results from the British Society for Rheumatology Biologics Register for Rheumatoid Arthritis. Ann Rheum Dis 2015;74:1087-93.

17. Singh JA, Furst DE, Bharat A, Curtis JR, Kavanaugh AF, Kremer JM, et al. 2012 update of the 2008 American College of Rheumatology recommendations for the use of disease-modifying antirheumatic drugs and biologic agents in the treatment of rheumatoid arthritis. Arthritis Care Res 2012;64:625-39. 